\title{
Countermeasure Research in Supplies Chain Management of Business Trading Company
}

\author{
Chen Xiaochun \\ Business School, Beijing Wuzi University, Beijing, China
}

Email address:

327640307@qq.com, chenxiaochun_77@163.com

To cite this article:

Chen Xiaochun. Countermeasure Research in Supplies Chain Management of Business Trading Company. Science Research. Vol. 4, No. 4, 2016, pp. 103-106. doi: 10.11648/j.sr.20160404.12

Received: August 9, 2016; Accepted: August 18, 2016; Published: August 25, 2016

\begin{abstract}
To accelerate the development mode of transformation in Business trading company under the background of economic globalization, is not only related to the efficiency and benefit of the trade circulation industry, but also related to improve people's living standard and quality of life. It provides a new way to enhance core competence of business trading company by using of Supply chain management. Therefore, how to strengthen procurement and supply chain management of business trading company, how to find a feasible method of improving the capability of information sharing between the member of supply chain, and how to enhance supply chain members cooperate to obtain the advantage in the fierce competition market, has become an important problem which need to be solved urgently by business trading companies.
\end{abstract}

Keywords: Business Trading Company, Supply Chain Management, Countermeasures

\section{Introduction}

\subsection{Current Situation of Purchasing and Supply Chain Management of Business Trading Company}

By the end of 2015, Total retail sales of consumer goods have reach to 30.1 Trillions, rose by $10.7 \%$ year-on-year, business trading industry as an important pillar of the expansion of consumption help China's GDP growth of 7.4\%. In recent years, China's total retail sales of consumer goods have reached a steady growth stage, as shown in figure 1:

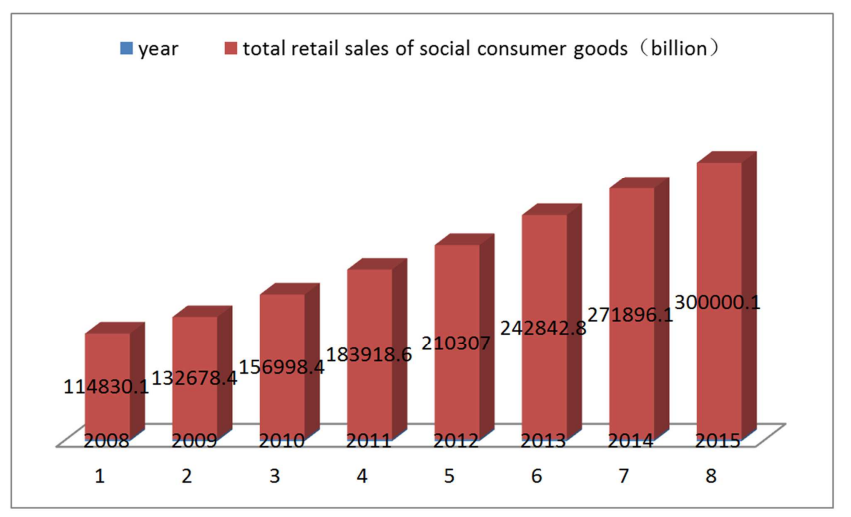

Figure 1. 2008-2015 total retail sales of social consumer goods in China.
Trading companies began to engage in the wholesale, retail, catering, accommodation, car, and so on. Consumer demand is moving in the direction of diversification and individuation; we can see that great changes have taken place in the service market. In order to maintain the total retail sales of social consumer goods increasing via such means as reduce costs, reduce waste; promote business competitive strength, the introduction of supply chain management, resource sharing, and collaborative development [1]. At present, business trading company has carried out the reform of supply chain management to improve the capability of service.

\subsection{The Supplier Cooperation Mechanism has Become More and More Important}

The opportunities of growth still exist under the economic environment in China. It can be optimize the supply chain management through closer to zero cooperation for business trading company. Establish long-term cooperative partnership with suppliers and share the common development opportunities with an open mind. Business trading company pay more and more attention to cooperation with suppliers, for example, the sales of Erie growth of more than 20\% year-on-year in 2013, Erie has established cooperative relations with more than 7000 suppliers. Wall Mart has also imposed retail link that can provide sales situation for 
suppliers, Close cooperation with suppliers can not only develop more quality products according to customer's requirement, but also can help suppliers to grasp the trend of consumption and market opportunities.

\subsection{The Internet is Gradually Integrated into the Supply Chain Collaborative Management}

With the development of computer net technology and Internet, the mode of supply chain management has changed greatly. Under the influence of electronic commerce, business trading company is no longer dependent on economies of scale, and more dependent on the reaction speed to the market, such as Improve development processes and productivity, inhibit the asymmetric information, which requires enterprises make full use of network information technology to improve the circulation organization and the level of modernization. The Internet is actually the Internet for collaborative, online retail can realize coordinate information flow and logistics, so that the members of the supply chain who retailers and logistics service providers and suppliers are able to form a community of interests, which help enterprises to implement purchase and supply chain collaborative management [2]. Online retail market has begun to grow since 2009, in recent years, the growth rate was higher than $40 \%$.

2009-2015 online retail market transactions as shown in figure 2:

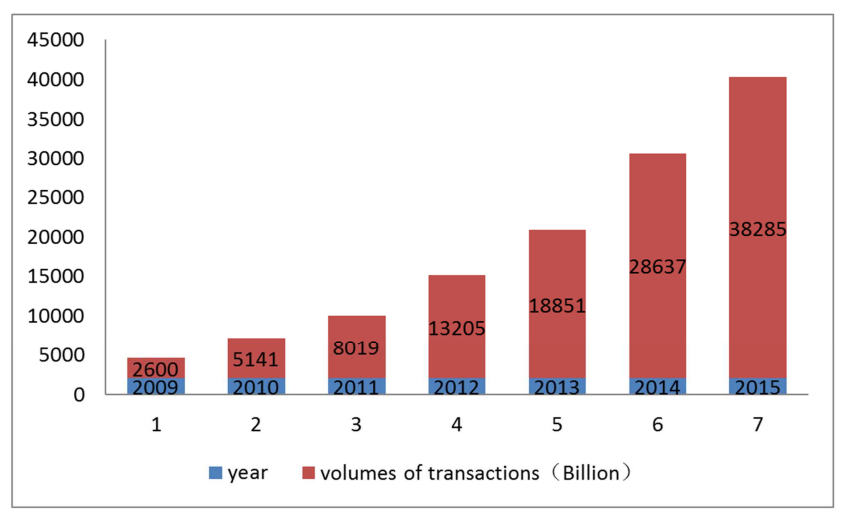

Figure 2. 2009-2015 Online retail market transactions in China.

\subsection{Constantly Innovate in the Model of Purchasing and Supply Chain Management}

The business enterprise can form new competitive power, new economic benefit, shorten the length of supply chain, and improve the efficiency of supply chain through constantly innovate in the model of purchasing and supply chain management. Su Ning construct strategic structure of "store + Su Ning Tesco and Tesco official" to open the backstage management system for suppliers, the supplier can see his sales situation at any time [3]. Through the opening of the "trusteeship" background systems, Su Ning not only can strengthen the source of supply chain cooperation, but also save the cost of supply chain management. In 2013, Hai Di Lao Hot Pot effort to build a new mode of chain supply chain platform, the background of supply chain truly realized the entire network service platform, centralized purchasing, centralized central kitchen processing.

\section{The Main Problems in Supply Chain Management of Business Trading Company}

There are some problems in the rapid development of business trading company, and the main problems in the procurement and supply chain management are as follows:

\subsection{Lack of Quality Control in Supply Chain}

business trading enterprises including various categories, The efficiency of traditional distribution channel is low, and the purchasing cycle is long, quality security system is not perfect, the supplier's quality assurance ability failed to carry out effective supervision, With the rapid development of e-commerce, enterprise more and more hope to improve procurement efficiency and reduce procurement costs through the emerging e-commerce platform, But there is lack of effective supervision in the network virtual environment and increase the risk of purchasing quality [4]. In addition, some enterprises lack of attention to the supplier relationship management, have not set up the supplier related files, cannot be informed of the dynamic information timely, most enterprise's management of suppliers still in the supplier's access and knockout stage, a lack of quality assurance ability may lead to supply chain quality management problems and affect the supply chain's overall operating efficiency.

\subsection{The Low Utilization Rate of Electronic Procurement}

Statistical data show that, for most enterprises, reducing $1 \%$ of the purchasing cost can make more than $8 \%$ of profit contribution, thus we can see the importance of procurement in the production and operation of enterprises. Now China is still in the process of the development of electronic commerce, a part of business trading enterprises have yet to establish the modern information communication platform, they failed to recognize the advantages of e-procurement [5]. In the wholesale industry, for example, although there is already construct the modernization of e-commerce trade platform, most of the wholesale enterprises is small scale, they don't understand the procurement department is the source of the company's profit, they did not realize that to achieve product differentiation through the procurement management.

\subsection{The Weak Ability of Information Sharing of the Supply Chain Enterprises}

There are dual relationship of competition and cooperation between business enterprises and its supply chain member.

Most supply chain members lack of trust and communication lead to information asymmetry, little consideration the interests of enterprises lead to uneven distribution of interests and Supply chain collaboration is not high. There is not solid of strategic cooperation foundation 
between the supply chain members. A lack of trust among members of the supply chain leads to seriously affect the relationship between the supply chain cooperation enterprises.

Supply chain is a whole that need to coordinate each node of member enterprises, only in this way can achieve the optimization of supply chain, if there is low information sharing ability of supply chain members and enterprise cannot Keep up with the development of the information times will bring some obstacles to the development of enterprises. According to a report couplet dealer network released, 2014 major domestic retail enterprises closed 201 stores, and compared to the number of 2013 , the surge in $474.29 \%$.

\subsection{The Efficiency of the Whole Supply Chain is Low}

The overall effectiveness of the supply chain depends on the effectiveness of the various supply chain nodes, the various departments have their own functions and have their own goals and objectives of the independent in the internal organizational structure of the business enterprise. However, it is not relevant between some of the goals and the overall objective of the supply chain is even not compatible. Due to various reasons the lack of a certain convergence between the various departments, resulting in low efficiency of the whole supply chain. For example, some enterprises will look for a small and can accept low prices supplier in order to achieve the aim in the procurement department.[6]

As a result, the purchasing department may complete their goal, but other department will be very cumbersome and inefficient because the supplier delivery is not timely, delivery quantity is not enough and other reasons, some enterprises and suppliers have their own warehouses in the process of actual operation, which may be cause huge waste. So if only there is an optimization in each node cannot stand the optimization of entire supply chain.

\section{Supply Chain Management Countermeasure of Business Trading Company}

\subsection{Control the Quality of the Supply Chain Strictly}

In order to control the quality of supply chain management and to optimize the develop environment of commercial distribution channels. Firstly, we need to actively carry out intellectual property protection and management work for trade circulation enterprises, crack down on violations of intellectual property rights and producing and strengthen patent protection to implement brand strategy. Secondly, improve the product quality control and establish quality management assurance system, through the perfect strict careful purchase and sales system, establish a smooth channel, perfect a long-term supervision mechanism, and expand the network of regulatory responsibilities and the implementation of effective supervision.

In the SCM, the enterprises in the neighborhood of supply chain act as vendor and buyer respectively. [7] To construct a complete and effective supply chain quality assurance system, strengthen the entire supply chain management, ensure the ability of supply chain continuous stable quality, rapid response and provide quality products and services to meet the user and market demand. Finally, improve quality management awareness and ability of staff through set up perfect sales records, education and training of relevant personnel.

\subsection{Improve the Visual Level of Supply Chain Management}

Data show that as of the end of 2014, the number of online shopping has reached 3.6 million people in China, almost a quarter of the proportion of the population, become the largest online retail market in the world, the use of the Internet simplifies the traditional consumption of circulation, also solve the information asymmetry problem of businesses and consumers. So improve the visualization level is a trend to strengthen the application of network in the supply chain management. The modern supply chain management relates to the information flow, logistics and capital flow, enterprises can achieve part or all of the supply chain transactions in e-commerce platform, can achieve the communication of inter enterprise, timely understanding of customer demand and supply situation. [8] Effective Supply chain management is helpful to strengthen ability to compete, improve service and enhance profit. [9]

Procurement as an important part of supply chain management, procurement network can reduce the intermediate circulation and improve the efficiency of supply chain. The most critical of making use of procurement network is how to establish a supply chain coordination platform, if only move procurement to online, each node will become an isolated island. In order to avoid this problem, we can improve the efficiency of logistics, capital flow and information flow in the supply chain by introducing a similar procurement information system. Procurement network system diagram shown in figure 3 :



Figure 3. Procurement network system flow chart.

\subsection{Establish the Mechanisms of Trust and Benefit Distribution}

With increasingly fierce market competition of business trade enterprises, through shorten the response time of each link, to improve the efficiency and reduce the cost, which requires strengthening the communication of member enterprises in the supply chain, enhancing the capability of 
information sharing, and ensure the quality and level of service.

Firstly, establish an effective mechanism to protect trust relationship in the field of business enterprises. Through establish the trust mechanism of supply chain, strengthen close cooperation between suppliers in internal enterprises and manufacturers of different departments to ensure timely on-demand supply. Secondly, establish the mechanism of benefits distribution in the running process of the enterprise, the benefits and risks is the presence, each of the supply chain enterprises to obtain benefits at the same time also to assume certain risks. Information sharing and cooperation in the members of supply chain enterprises, not only can reduce the cost of the whole supply chain, but also improve the service level of supply chain and accelerate the flow of logistics and capital to achieve win-win situation. That Can not only accelerate the response time when whole supply chain face market, but also can maximize reduce the logistics cost of whole supply chain, which can achieve the purpose of tapping the potential synergies and increase income and reduce expenditure.

\subsection{The Formation of a Rapid Response Mechanism}

Strengthen the coordination of the whole supply chain, starting from the customer relationship to the end of the relationship, which not only include the relationship with suppliers but also with the downstream customers. Vendor selection is important in supply chain management. [10] Business enterprise can make rapid response to the whole supply chain market by using a seamless connection system of B2B, ERP, B2C, CRM and HR. In 2014, Yushang network is committed to build on the downstream partners sharing platform based on line market, in order to create the Internet throughout the supply chain and build a new B2B trading platform for upstream brands, downstream retail customers to communication. The form of enterprise competition gradually shifts from individual enterprise throughout the competition among the whole supply chain. Enterprise business collaboration in the supply chain is becoming more frequent. Through the implementation of the whole supply chain management to help customers to achieve the best allocation of resources and the best plans for accomplishing goals, control the total cost, reduce the risk of external market, so as to improve supply chain efficiency, strengthen the competitive power. In addition to, it also requires all members take participation in supply chain management, form a smooth supply chain system to improve the efficiency of the whole supply chain, Therefore, member enterprises must support and cooperate with each other in all aspects in order to promote the high-speed operation of the enterprise.

\section{Conclusion}

Research on existing question and countermeasure in supplies chain management of business trade Enterprise in China, we can know that the development of electronic commerce has changed the way that enterprises use the supply chain to gain competitive advantage, the development of E-business also give a new chance to supply chain management. Therefore, it is meaningful to study the theory and technique of supply chain management to improve the management and competitiveness of modern enterprises in theory and in practice. In the future research, it is necessary to study supplies with the coordination problem of the information sharing among chain members to analyze and solve information asymmetry of supply chain. However, examination needs improving and perfecting in subsequent.

\section{References}

[1] $\mathrm{Lu} \mathrm{Lu}$. Speed up the transformation of the development of trade industry [J]. China Economic and trade, 2010 (11).

[2] High Zhifei. Study on the purchasing management of WAL-MART retail in China [J]. Business economics, 2013 (04).

[3] Kang Yulan. Analyze the market modernization development of supply chain management [J]. Business Management, 2012 (07).

[4] Si Zengzhuo. Research of China's commercial circulation Chuo recognition industry chain and Optimization [J]. jianghai academic journal, 2014 (05).

[5] Pan Feng. Research on supply chain procurement management of retail e-commerce enterprises [J]. Lanzhou University of Technology, 2013 (06).

[6] Ye Zhiyang, Xie Xie. Research on purchasing management strategy under supply chain management $[\mathrm{J}]$. business culture, $2011(02)$

[7] Qin yan. Actively carry out against IPR infringement and selling fake and inferior commodities initiative in the field of commercial and trade circulation $[\mathrm{J}]$. Science and technology of logistics. 2011 (03).

[8] Chen Pingli. Discussion on supply chain and enterprise procurement management [J]. Economic Management, 2013 (02).

[9] Liu Rong. Research on risk control strategy of retail enterprise supply chain [J]. Logistics Engineering and Management, 2015 (01).

[10] Wang Bin. Research on material purchasing strategy of enterprise based on supply chain management [J]. Chemical Engineering Management, 2015 (06). 